\title{
The accuracy of creatinine clearance with and without urine collection as a measure of glomerular filtration rate
}

\author{
D.G. Waller, ${ }^{1}$ J.S. Fleming, ${ }^{2}$ B. Ramsay ${ }^{1}$ and J Gray ${ }^{2}$ \\ ${ }^{1}$ Clinical Pharmacology Group and ${ }^{2}$ Department of Nuclear Medicine, Southampton General Hospital, \\ Southampton SO9 4XY, UK.
}

\begin{abstract}
Summary: Conventional creatinine clearances involving urine collections over 2, 4 and 24 hours and creatinine clearance predicted from plasma creatinine concentrations without urine collection were compared to glomerular filtration rate (GFR) estimated by ${ }^{99 m}$ Tc DTPA clearance in 171 patients with a wide range of GFR.

All creatinine clearance methods involving urine collection had standard errors of the estimate of GFR greater than predictions from formulae.

Predictions of creatinine clearance by formulae had coefficients of variation of the estimate of approximately $23 \%$ when compared to isotopically determined GFR.

Creatinine clearances determined by these equations in patients with stable renal function are an easier and at least as accurate a guide to GFR as methods involving urine collection.
\end{abstract}

\section{Introduction}

Serum creatinine concentrations are a poor guide to glomerular filtration rate (GFR) since they are highly dependent on muscle mass and are insensitive to changes in renal function until GFR is substantially reduced. ${ }^{1}$ When a direct measure of GFR is required, as for adjusting drug dosage, the ideal method would be to measure the renal clearance of an isotopically labelled chelate. Facilities for this are not always available and consequently, 24 hour endogenous creatinine clearance is still employed. Obtaining accurate timed urine collections is one major potential source of error when determining creatinine clearances, and to reduce this, considerably shorter collection times have been proposed. ${ }^{2}$ However, correlations between creatinine clearances calculated from 24 hour and shorter timed collections have not been close.

To overcome the need for urine collections, several formulae and nomograms have been devised to predict creatinine clearance from the plasma creatinine concentration, taking the age, sex and body weight of the subject into account. These predictions are possible since urine creatinine excretion is fairly constant across a wide range of renal function when adjusted for the patients' physical characteristics. There have been few comparisons of both measured and predicted creatinine clearances with an accurate measure of GFR. We have used the plasma clearance of ${ }^{99 m} \mathrm{Tc}$

Correspondence: D.G. Waller, D.M., M.R.C.P.

Accepted: 7 August 1990
DTPA as a reference standard and compared the ability of various measured or predicted creatinine clearances to estimate the GFR.

\section{Patients and methods}

One hundred and seventy-one patients with stable renal function, who were undergoing radioisotopic estimation of GFR as part of their clinical management, were studied. Plasma clearance of ${ }^{99 \mathrm{~m} T c}$ DTPA (Pentetate II, Amersham International) was calculated from blood samples taken 2 and 4 hours after injection. ${ }^{3}$ Urine was collected by spontaneous voiding between 0 and 4 hours post injection ( 37 patients) or between 0 and 2 hour (92 patients). A further 35 patients brought an unsupervised 24 hour urine collection from home having received full written instructions. These collections finished on the morning of the GFR measurement.

Measured creatinine clearances were obtained using the 24, 4 and 2 hour urine collections and a plasma creatinine taken 2 hours post isotope injection on the study day. Predicted creatinine clearances were derived from the plasma creatinine using the formulae of Hull et al. ${ }^{4}$ and Cockcroft and Gault $^{5}$ (Figure 1), and the nomogram of Bjornsson et al..$^{6}$ Plasma and urine creatinine were measured using a Vickers automated multi-channel analyser.

Predicted creatinine clearances may be overestimated in patients with marked obesity. ${ }^{4}$ There- 
1. Cockcroft and Gault ${ }^{5}$

$$
\begin{aligned}
& \text { Males } \operatorname{Ccr}=1.23 \times \frac{(140 \text {-age in years }) \times(w t \text { in } \mathrm{kg})}{\text { plasma creatinine } \mu \mathrm{mol} / \mathrm{l}} \\
& \text { Females } \\
& \qquad \mathrm{Cr}=1.04 \times \frac{(140 \text {-age in years }) \times(w t \text { in } \mathrm{kg})}{\text { plasma creatinine } \mu \mathrm{mol} / \mathrm{l}}
\end{aligned}
$$

2. Hull et al. ${ }^{4}$

$$
\begin{aligned}
& \mathrm{Ccr}=1.26 \times \frac{(145 \text {-age in years }) \times(w t \text { in } \mathrm{kg})}{\text { plasma creatinine } \mu \mathrm{mol} / \mathrm{l}}-3 \\
& \text { Females } \\
& \mathrm{Ccr}=1.04 \times \frac{(145 \text {-age in years }) \times(w t \text { in } \mathrm{kg})}{\text { plasma creatinine } \mu \mathrm{mol} / \mathrm{l}}-3
\end{aligned}
$$

Figure 1 Equations evaluated for the prediction of creatinine clearance $(\mathrm{Ccr})$.

fore, when body weight was $>30 \%$ above ideal, the latter value was used in the equations and nomogram.

Correlations between the estimates from each creatinine clearance technique and reference isotopic GFR were obtained by least squares analysis, and the standard error of the estimate of GFR and the corresponding coefficient of variation calculated in each case. The significance of differences between coefficients of variation was determined by the $F$ test.

To assess whether there was any systematic difference in the values of the creatinine clearances compared to the reference isotopic GFR, paired Student's $t$-tests were performed.

In addition to the above calculations, the values on subjects with isotopic GFR below $50 \mathrm{ml} / \mathrm{min}$ and those above $50 \mathrm{ml} / \mathrm{min}$ were analysed separately. In each case the mean differences between the creatinine clearance values and GFR were assessed using a paired Student's $t$-test.

\section{Results}

A summary of the correlations between the various methods for deriving creatinine clearance and the reference GFR obtained from plasma clearance of ${ }^{99 m}$ Tc DTPA is shown in Table I. The relationships between predicted or measured creatinine clearance and reference GFR all tended to demonstrate an increasing absolute error in the estimate of GFR with higher GFR values (Figure 2). It was therefore considered more appropriate to use a measure of the relative dispersion (the coefficient of variation) rather than the absolute dispersion when comparing the accuracy of estimation of the different techniques.

The Cockcroft and Gault and Bjornsson predictions of creatinine clearance showed no systematic difference from GFR whereas the Hull equation gave a small but significant overestimate $(P<$ 0.01 ). The coefficients of variation of estimating GFR were similar for both equations and the nomogram. The relationship between GFR and the Cockcroft and Gault prediction of creatinine clearance is shown in Figure 2.

The measured creatinine clearance techniques all produced systematically higher values compared to reference GFR. The coefficient of variation of estimating GFR from the 2 hour clearances was significantly higher than both the 4 and 24 hour clearances $(P<0.01)$.

The coefficients of variation of estimating GFR using the formulae or nomogram were significantly

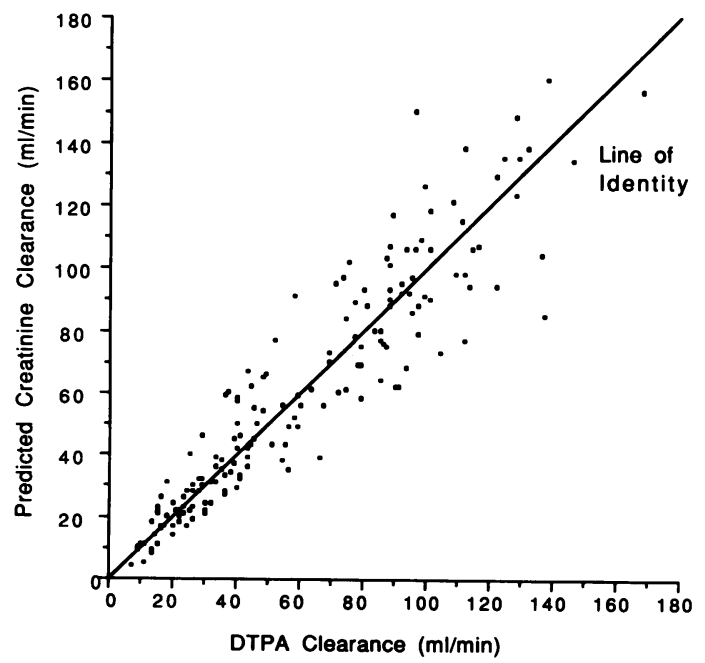

Figure 2 Regression relationship between glomerular filtration rate measured by plasma clearance of ${ }^{99 m} \mathrm{Tc}$ DTPA and predicted creatinine clearance by the method of Cockcroft and Gault. 


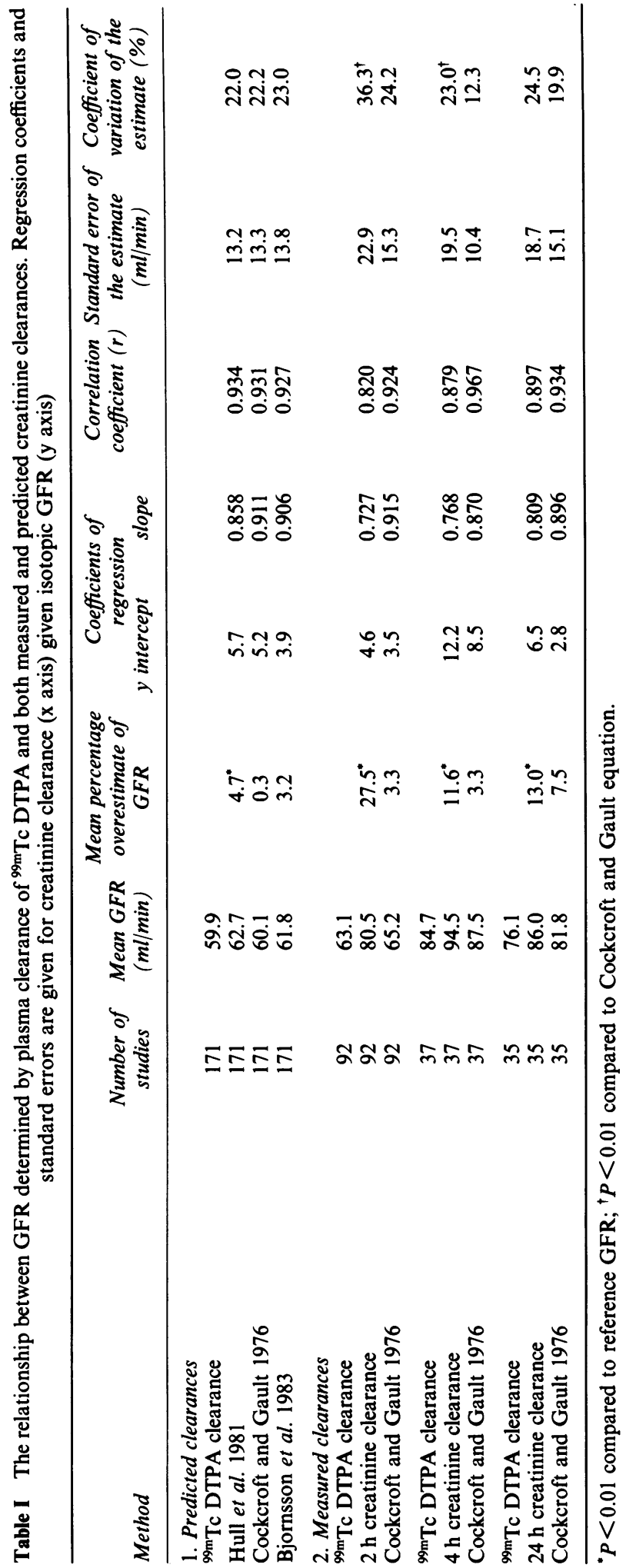


lower than those of the 2 and 4 hour measured creatinine clearances $(P<0.01)$ and showed a trend to a lower error than for the 24 hour measured clearance.

The differences between measured creatinine clearances and reference GFR for subjects with GFR greater or less than $50 \mathrm{ml} / \mathrm{min}$ are shown in Table II. In each case the mean creatinine clearance values were higher than the reference GFR. In addition the relative overestimate was higher when the GFR was less than $50 \mathrm{ml} / \mathrm{min}$ than when it was greater than $50 \mathrm{ml} / \mathrm{min}$, although only for the 2 hour clearance values was this statistically significant. The results for the Cockcroft and Gault predicted creatinine clearance showed closer agreement across the whole GFR range than measured creatinine clearances.

\section{Discussion}

Plasma clearance of ${ }^{99 m}$ Tc DTPA has been shown to accurately reflect GFR measured by inulin clearance, provided a preparation with low protein binding is used. ${ }^{7}$ The technique used for measurement of the reference GFR in this study gives a standard error of the estimate of less than $3 \mathrm{ml} / \mathrm{min}$ when compared to multiple plasma sampling. ${ }^{3}$ This should therefore provide an acceptably accurate standard with which to compare the creatinine clearances. The many potential sources of error in the measurement of creatinine clearance, which include the laboratory methods for measuring creatinine and the accuracy of urine collection, have been reviewed by Bjornsson. ${ }^{1}$ The current study demonstrated the inaccuracy of all the creatinine clearance estimates when compared with isotope clearance GFR and agrees with previous assessments. $^{8}$

Measured creatinine clearance tends to overestimate low GFR. ${ }^{9,10}$ In the current study, the measured creatinine clearances gave a considerable overestimation of the mean GFR, most marked at low GFR.
By contrast, the Cockcroft and Gault predicted creatinine clearances showed a smaller mean overestimate at low GFR and an underestimate at high GFR. Charleson et al. ${ }^{11}$ demonstrated a correlation of 0.83 between predicted creatinine clearance by the method of Cockcroft and Gault and ${ }^{51}$ chromium EDTA clearance. The regression equation was not given but the scatter diagram suggested that the equation gave a similar overestimation of GFR at low creatinine clearances with an underestimate at high clearances.

The reliability of the predicted creatinine clearances in determining GFR in the current study is similar to those found by previous workers, who calculated reliability to be between $\pm 21-35 \%{ }^{12,13}$ Brochner-Mortensen ${ }^{14}$ suggested that 24 hour creatinine clearance is more reliable than predicted clearances, but based this conclusion on data from the mean of three urine collections discarding patients with variable results from the analyses. The comparisons from our study suggest that measured creatinine clearance in clinical practice, even with short supervised urine collection periods, is likely to be no better than and probably less accurate than predicted clearances.

The limitations of the prediction methods have been reviewed recently by Smith. ${ }^{15}$ In patients with marked obesity predicted creatinine clearance will overestimate true GFR ${ }^{4}$ and in this situation, ideal body weight can be used in the equations to improve accuracy. Prediction methods should also be avoided in patients with hepatic dysfunction, 5,16 and if renal function is rapidly changing. Application of this approach without consideration of such factors may have contributed to the conclusions of other investigators that the coefficient of variation of predicted creatinine clearance was too great for it to be of clinical value. ${ }^{17-20}$

Creatinine clearance is a more easily interpreted index of renal function than serum creatinine alone. Our results suggest that predicted creatinine clearance provides a simpler and probably more accurate alternative to measured clearances for determining GFR. Nevertheless, it should be

Table II Percentage ( \pm standard error) overestimate between creatinine clearances relative to isotopic GFR for subjects with GFR less than $50 \mathrm{ml} / \mathrm{min}$ compared to those with GFR greater than $50 \mathrm{ml} / \mathrm{min}$

\begin{tabular}{lccc}
\hline & $\begin{array}{c}\text { GFR less } \\
\text { than } \\
50 \mathrm{ml} / \mathrm{min}\end{array}$ & $\begin{array}{c}\text { GFR greater } \\
\text { than } \\
50 \mathrm{ml} / \mathrm{min}\end{array}$ & $\begin{array}{c}\text { Significance } \\
\text { of difference }\end{array}$ \\
\hline 2 h Creatinine clearance & $61 \pm 12$ & $18 \pm 4$ & $P<0.005$ \\
4 h Creatinine clearance & $16 \pm 10$ & $11 \pm 5$ & N.S. \\
24 h Creatinine clearance & $28 \pm 15$ & $11 \pm 4$ & N.S. \\
Cockcroft and Gault & $6 \pm 3$ & $-2 \pm 2$ & $P<0.05$ \\
\hline
\end{tabular}


remembered that all methods for determining creatinine clearance are inaccurate and that isotopic estimations of GFR are desirable when greater precision is required.

\section{References}

1. Bjornsson, T.D. Use of serum creatinine concentrations to determine renal function. Clin Pharmacokinet 1979, 4: 200-222.

2. Richardson, J.A. \& Philbin, P.E. The one hour creatinine clearance rate in healthy men. JAMA 1971, 216: 987-990.

3. Waller, D.G., Keast, C.M., Fleming, J.S. \& Ackery, D.M. Measurement of glomerular filtration rate with Tc $99 \mathrm{~m}$ DTPA: Comparison of plasma clearance techniques. $J \mathrm{Nucl}$ Med 1987, 28: 372-377.

4. Hull, J.H., Lawrence, J.H., Kock, G.G., Wargin, W.A., Shelly, L.C. \& Mattocks, A.M. Influence of range of renal function and liver disease on predictability of creatinine clearance. Clin Pharmac Ther 1981, 29: 516-521.

5. Cockcroft, D.W. \& Gault, M.H. Prediction of creatinine clearance from serum creatinine. Nephron 1976, 16: 31-41.

6. Bjornsson, T.D., Cocchetto, D.M., McGowan, F.X., Verghese, C.P. \& Sedor, F. Nomogram for estimating creatinine clearance. Clin Pharmacokinet 1983, 8: 365-369.

7. Rehling, M., Moller, M.L., Thamdrup, B., Lund, J. \& Trap-Jensen, J. Simultaneous measurement of renal clearance and plasma clearance of $99 \mathrm{mTc}$ DTPA, 51Cr EDTA and inulin in man. Clin Sci 1984, 66: 613-619.

8. Brochner-Mortensen, J. \& Rodbro, P. Selection of routine method for determination of glomerular filtration rate in adults. Scand J Clin Lab Invest 1976, 36: 35-43.

9. Miller, B.F., Leaf, A.L., Mamby, A.R. \& Miller, Z. Validity of the endogenous creatinine clearance as a measure of glomerular filtration rate in the diseased human kidney. $J$ Clin Invest 1952, 31: 309-313.

10. Hagstam, K.E., Nordenfelt, I., Svensson, L. \& Svensson, S.E. Comparison of different methods for determination of glomerular filtration rate in renal disease. Scand J Clin Lab Med 1974, 34: 31-36.

\section{Acknowledgements}

We thank Sue O'Toole for nursing assistance, the Chemical Pathology staff for creatinine clearance analyses and Dianne Wilson for typing the manuscript.

11. Charleson, H.A., Bailey, R.R. \& Stewart, A. Quick prediction of creatinine clearance without the necessity of urine collection. NZ Med J 1980, 92: 425-426.

12. Brochner-Mortensen, J., Jensen, S., \& Rodbro, P. Assessment of renal function from plasma creatinine in adult patients. Scand J Urol Nephrol 1977, 11: 263-270.

13. Heierli, Ch., Thölen, H. \& Bartels, H. Schätzung des glomerulumfiltrates durch das serum kreatinin. Dtsch Med Wochenschr 1972, 97: 67-70.

14. Brochner-Mortensen, J. Routine methods and their reliability for assessment of glomerular filtration rate in adults. Dan Med Bull 1978, 25: 181-202.

15. Smith, S.A. Estimation of glomerular filtration rate from the serum creatinine. Postgrad Med J 1988, 64: 204-208.

16. Cocchetto, D.M., Tschanz, C. \& Bjornsson, T.D. Decreased rate of creatinine production in patients with hepatic disease: implications for estimation of creatinine clearance. Ther Drug Mon 1983, 5: 161-168.

17. Rolin, H.A., Hall, P.M. \& Wei, R. Inaccuracy of estimated creatinine clearance for prediction of iothalamate glomerular filtration rate. Am J Kidney Dis 1984, 4: 48-54.

18. Trollfors, B., Alestig, K. \& Jagenburg, R. Prediction of glomerular filtration rate from serum creatinine, age, sex and body weight. Acta Med Scand 1987, 221: 495-498.

19. Trollfors, B., Alestig, K. \& Jagenburg, R. Prediction of glomerular filtration rate from changes in serum creatinine. Scand J Clin Lab Invest 1988, 48: 85-90.

20. Groth, S., Aasted, M. \& Vestergaard, B. Screening of kidney function by plasma creatinine and single-sample ${ }^{5 T} \mathrm{Cr}$ EDTA clearance determination - a comparison. Scand J Clin Lab Invest 1989, 49: 707-710. 